\title{
Mediações da informação: sentidos sócio-históricos
}

\section{Ana Amélia Lage Martins ${ }^{I}$ \\ http://orcid.org/ 0000-0001-6296-3441}

Regina Maria Marteleto ${ }^{I I}$

http://orcid.org/0000-0002-3439-0217

${ }^{I}$ Universidade Federal do Estado do Rio de Janeiro, RJ, Brasil.

Doutora em Ciência da Informação pela Universidade Federal de Minas Gerais.

${ }^{I I}$ Instituto Brasileiro de Informação em Ciência e Tecnologia, RJ, Brasil.

Doutora em Comunicação e Cultura pela Universidade Federal do Rio de Janeiro.

http://dx.doi.org/10.1590/1981-5344/4140

O termo mediação apresenta-se no campo de estudos da informação como importante categoria que orienta o olhar para as diferentes questões relacionadas à produção, acesso, consumo, apropriação e organização de informações. Considerando a relevância que o termo adquiriu na Ciência da Informação e a polissemia que marca o seu uso, o artigo tem em vista apresentar reflexões derivadas de pesquisa de pós-doutorado que buscou, dentre outros objetivos, explorar a gênese histórica e filosófica do termo, bem como apontar perspectivas do seu uso na construção e apreensão dos objetos info-comunicacionais na contemporaneidade. Para tanto, investiga as raízes do conceito na dialética (G.W.F. Hegel; K. Marx) e sua reformulação por meio do construto 
"mediação social" no campo comunicacional (M. Martín Serrano). Finalmente, consideram-se abordagens de linhagem francesa das Ciências da Informação e da Comunicação (Y. Jeanneret; J. Davallon) sobre a economia das escritas na web, com foco nas micro-formas documentárias. Essas diferentes abordagens mostram-se complementares no sentido de abarcar diferentes planos das mediações da informação - macro e micro sociais, teórico-conceituais e empírico-aplicados, documentários e processuais - em suas múltiplas e relacionais determinações.

Palavras-chave: mediação e informação. Materialismo histórico. Conhecimento e tecnologia. Mediação social.

\section{Information mediations: socio- historical meanings}

The term mediation is presented in the field of information studies as an important category that guides the different issues related to the production, access, consumption, appropriation and organization of information. Considering the relevance in which the term acquired in Information Science and the polysemy that marks its use, the article aims ate presenting reflections derived from postdoctoral research that sought, among other objectives, to explore the historical and philosophical genesis of the term, as well as point out perspectives of its use in the construction and apprehension of info-communicational objects in contemporary times. To this end, it investigates the roots of the concept in dialectics (G.W.F. Hegel; K. Marx) and its reformulation through the construct "social mediation" in the communicational field (M. Martín Serrano). Finally, we consider French lineage approaches of Information and Communication Sciences ( $Y$. Jeanneret; J. Davallon) on the economics of writing on the web, focusing on micro- 
documentary forms. These different approaches are complementary in a way that they encompass different levels of information mediation - macro and micro social, theoretical-conceptual and empirical-applied, documentary and procedural - in their multiple and relational determinations.

Keywords: mediation and information. Historical materialism. Knowledge and technology. Social mediation.

Recebido em 30.09.2019 Aceito em 23.03.2021

\section{Introdução}

Uma das ideias mais recorrentes nos planos teórico e aplicado do campo informacional é, atualmente, a mediação, categoria empregada para compreender e caracterizar diferentes questões e práticas relacionadas às dinâmicas de produzir, distribuir, acessar e organizar informações e conhecimentos. No Brasil, sua integração ao quadro teórico da Ciência da Informação e da Comunicação deu-se, especialmente, a partir da emergência de uma "epistemologia social da informação" (MARTELETO, 2015), da discussão da cultura como campo de articulação da hegemonia (ALMEIDA, 2007); da influência de Martin-Barbero (1987) que propôs reorientar o objeto da comunicação dos "meios para as mediações", sendo sua atual consolidação também influência dos trabalhos de Bruno Latour, da abordagem das redes sociais (PORTUGAL, 2007) e de outros autores filiados a uma "epistemologia reticular", que situam as "mediações" como importante categoria do pensamento.

Considerando a relevância, tanto teórica quanto prática, que o termo alcançou nas últimas décadas, o artigo tem em vista apresentar questões suscitadas em pesquisa que buscou explorar a gênese histórica e filosófica do termo, como modo de contribuir com sua fundamentação teórica e epistemológica na construção e apreensão dos objetos infocomunicacionais.

Tal investigação, de natureza teórica, buscou compreender a mediação, em primeiro momento, a partir de um importante marco de desenvolvimento da categoria: a dialética moderna. A retomada dos elos 
histórico-filosóficos do conceito a partir de obras de referência da Filosofia (ABBAGNANO, 2007; JAPIASSÚ, MARCONDES, 2001; MORA, 1982; LEGRAND, 1991) confirma a mediação como categoria desenvolvida pela dialética moderna, primeiramente em Hegel e, subsequentemente, em Marx. A necessidade de investigar sua função e operação neste sistema filosófico, onde desempenha um papel, segundo Bottomore (2010), de "categoria central", tornou-se, neste sentido, premente.

No quadro da dialética, a mediação é, de maneira geral, um operador lógico e histórico que apreende o real e os objetos a partir do processo de sua contradição constitutiva e dos nexos estabelecidos no âmbito de uma totalidade histórica complexa. Sua operação está fundamentalmente vinculada ao momento da negação e às noções de totalidade, historicidade, contradição, essência, aparência, forma, conteúdo, singular-particular-universal, transitoriedade e movimento. Ela expressa a interconexão universal de todas as coisas como condição de sua determinação concreta, a impossibilidade de apreensão de um objeto por sua manifestação imediata ou fenomênica e a necessidade de perseguir suas articulações, propondo a compreensão dos processos singulares à luz de sua particularidade histórica (CIAVATTA, 2001; MARTINS, 2019a).

Este momento inaugural da pesquisa permitiu identificar a mediação como dotada fundamentalmente de uma função ontológica (vinculada à produção do ser), lógica (relativa à estruturação do pensamento), epistemológica (relacionada à construção de conhecimento, que não se dá de maneira imediata) e metodológica (caminho para chegar ao conhecimento) (MARTINS, 2019a).

Em um segundo momento, o estudo procurou perceber de que modo a perspectiva dialética da mediação se refletia nos debates sobre a comunicação e a informação, o que nos conduziu à retomada dos trabalhos de Manuel Martín Serrano. Dez anos antes de Jesús MartínBarbero (1987), o autor publicou na Espanha, em 1977, o livro La Mediación Social, introduzindo a categoria mediação na base de uma proposta epistemológica e metodológica para a Comunicação, cuja perspectiva assinalava a mediação como operação lógica e histórica ligada à contradição.

A partir dos referenciais dialéticos foi possível perceber que a mediação pode ser uma categoria utilizada na construção e apreensão dos objetos informacionais como modo de complexificá-los a partir de perspectivas históricas que iluminam a relação necessária entre sentidos e significados produzidos nas práticas e processos informacionais, a produção econômica e a reprodução social (MARTINS, 2019a). 
Dentre os objetos emergentes no cenário digital passíveis de um olhar pelas mediações encontram-se as chamadas "micro-formas documentárias" (JEANNERET, 2015), os pequenos documentos que são produzidos e circulam pela Internet e que, assim como a formamercadoria, podem revelar aspectos essenciais do modo de produção e reprodução social do capitalismo, especialmente em sua forma atual. Aponta-se, neste sentido, como um olhar pelas mediações dialéticas a estes objetos incide na busca pelos seus nexos constitutivos de modo a evidenciar as relações entre pequenos objetos documentários, a constituição do capitalismo neoliberal e a produção de sujeitos adaptados a ele.

A pesquisa buscou, assim, indicar vias de aproximação entre a perspectiva dialética das mediações e a economia política dos textos e escritas na web (JEANNERET, 2015; MARTELETO, 2015), que apontam para a existência de uma dialética entre formatos documentários e as configurações das relações sociais.

\section{A mediação na dialética}

A dialética que Hegel desenvolveu como sistema filosófico no século XIX compreende um sistema das leis do movimento da realidade e, ao mesmo tempo, do pensamento que pensa a realidade. Ela tem como característica central a unidade de desenvolvimento entre o real e o racional e, ultrapassando a lógica formal, toma como seu princípio e fundamento a contradição.

Na dialética hegeliana a mediação tem, primeiramente, uma função ontológica1: é a operação que permite a determinação do ser, o qual se constitui no encontro com o não-ser e o vir a ser, se tornando a essência ou o próprio conceito. Este processo se caracteriza pela negação e pode ser: a) físico- por exemplo uma glande é imediata, mas o carvalho é mediado por um processo de crescimento ou b) epistêmico - o ser puro é imediato, mas sua essência é mediada por um processo lógico (INWOOD, 1997). A determinação do ser, o desenvolvimento do seu conteúdo é um processo que requer mediação.

O ser é o imediato indeterminado; ele está livre da determinação frente à essência, bem como ainda de cada determinidade que ele pode adquirir no interior de si mesmo. Este ser sem reflexão é o ser tal como ele é imediatamente apenas nele mesmo. Porque ele é indeterminado, ele é ser sem qualidade; mas em si, compete-lhe o caráter da indeterminidade apenas em oposição ao determinado ou ao qualitativo. Porém o ser determinado como tal se opõe ao ser em geral; com isso, contudo, sua indeterminidade mesma constitui sua qualidade. (HEGEL, 2016, p. 84). 
Hegel mostra, ao discutir a determinidade (qualidade) do ser, que, em sua imediatidade indeterminada, o ser é igual "apenas a si mesmo e não desigual frente ao outro", não tendo, portanto, nenhuma diversidade dentro de si nem para fora de si. É preciso uma mediação, que é a própria reflexão, para que o ser passe do ser imediato, (o ser com a certeza simples de si mesmo), para o ser aí (resultado da reflexão) e em terceiro momento para o ser para si (conceito-essência). Hegel assinala, contudo, que a imediatidade e a mediação sempre coexistem uma na outra: o serconceito desenvolvido pelas mediações é também imediato, já que em tudo que existe há o mediato e o imediato.

A função propriamente epistemológica e metodológica da mediação está ligada à impossibilidade do conhecimento imediato ou do acesso imediato à essência de um objeto, o qual é resultado do processo totalizador em que o movimento do real histórico e do real lógico se desenvolvem mutuamente. Assim, para Hegel, não se pode alcançar qualquer conhecimento refletido de forma imediata, sendo que a capacidade de conhecimento da razão tem na mediação uma função crucial do intelecto, já que é com base nele que se pode atribuir elementos de diferenciação no objeto ou sujeito a ser apreendido.

A função ontológica da mediação é evidenciada na dialética materialista de Marx na formulação do entendimento do trabalho como mediador da produção do metabolismo entre humanidade e natureza, sendo aquilo que permite a existência do ser social (MARX, 2011) e o desenvolvimento do gênero humano. Em sua perspectiva, o ser social somente existe se consegue satisfazer as necessidades do corpo, o que acontece por meio da atividade produtiva do trabalhoz, mediadora da relação dos humanos com a natureza e dos humanos entre si:

onde a necessidade de vestir-se o obrigou, o homem costurou por milênios, e desde muito antes que houvesse qualquer alfaiate. Mas a existência do casaco, do linho e de cada elemento da riqueza material não fornecido pela natureza teve sempre de ser mediada por uma atividade produtiva especial, direcionada a um fim, que adapta matérias naturais específicas a necessidades humanas específicas (MARX, 2011, p. 167, grifo nosso).

Marx evidenciou, no entanto, que a realização histórica destas mediações sob o capitalismo, a partir de um modo específico de organização das forças produtivas e das relações de produção, acabou por 
promover uma ruptura ontológica fundamental, na medida em que a constituição dos sujeitos tendeu a se orientar para os processos de valorização do capital e não para a satisfação plena das necessidades humanas (BOLAÑO, 2018; MARTINS, 2019b). O capital se converteu, assim, em sujeito e "o desenvolvimento das forças produtivas, que potencialmente abririam possibilidades emancipadoras, ficou limitado pelas relações de produção alienadas" (BOLAÑO, 2018, p. 103). Isto torna a produção das mediações no capitalismo marcada por um duplo caráter: libertador, na medida em que se constitui como atividade ontocriativa que produz o ser, e alienador, na medida em que se organiza tendo como fim a reprodução do próprio sistema. É neste sentido que as mediações que se interpõem em primeiro momento entre homens e mulheres e a natureza para a satisfação das necessidades possam ser pensadas como "mediações de primeira ordem" (mediações que visam assegurar a reprodução sociometabólica da espécie humana ) e as mediac ões que interditam ou impedem a realização das potencialidades humanas como "mediações de segunda ordem" (MÉSZÁROS, 2002).

Marx também coloca a categoria mediação na construção do conhecimento, indicando a necessidade metodológica de passagem do real empírico ao real concreto - pela mediação do abstrato; bem como assinalando a necessidade de se perseguir as "múltiplas determinações do real" (MARX, 2008) ou os nexos estabelecidos entre as partes de uma totalidade complexa.

Metodologicamente, a mediação vislumbra os fenômenos singulares a partir da sua particularidade histórica e por seus nexos constitutivos, o que implica em considerar de maneira central a totalidade, além da contradição. Problematizando por uma perspectiva dialética a mediação como categoria metodológica que lança luz sobre diversos aspectos do real, Ciavatta (2001) lembra que o termo está implicado, num primeiro momento, com a questão epistemológica da reconstrução histórica do objeto científico, ou "de como nos logramos aproximar da realidade" (CIAVATTA, 2001, p. 208).

Quando falamos em aproximação da realidade através da reconstrução histórica, duas questões preliminares estão postas: recusa de todo dogmatismo e das concepções evolucionistas da história, recusa da visão cética e fragmentada do mundo e do relativismo como ponto de partida. Aos sistemas explicativos fechados ou funcionais, a uma visão fragmentada da realidade propomos a busca das articulações que explicam os nexos e significados do real e levam à construção de totalidades sociais, 
relativas a determinados objetos de estudo (CIAVATTA, 2001, p. 210).

A autora chama a atenção para a relação intrínseca entre a categoria totalidade e a mediação, lembrando que a totalidade social construída não compreende uma racionalização ou modelo explicativo, mas um conjunto dinâmico de relações configurado pela ação de sujeitos sociais. Desse modo, ela não é apenas uma concepção mental, mas tem um referente histórico, material, social, moral ou afetivo, de acordo com as relações que constituem determinada totalidade (CIAVATTA, 2001).

Se para Hegel a "verdade é o todo", esta somente se completa mediante o seu desenvolvimento temporal em um processo totalizador, o que torna a essência, ou a verdade, inacessível imediatamente ao fenômeno, em sua manifestação singular ou individual, mas somente tendo em vista suas mediações. Trata-se, portanto, de uma categoria que coloca o objeto em relação com o todo (CIAVATTA, 2001 apud MARTINS, 2019a). A mediação constitui o percurso por meio do qual os nexos dialéticos de todo processo são expostos (KONDER, 2001), possibilitando o conhecimento do fenômeno, cuja essência não coincide com sua expressão externa, mas se apresenta sob uma forma ou aparência.

Conforme apontam Rosental e Strikes (1960), para o materialismo dialético, a essência e o fenômeno (aparência) são dois aspectos indissociavelmente vinculados da realidade objetiva. A essência refere-se ao aspecto interno, o qual não pode manifestar-se senão através do aspecto externo - o fenômeno. A partir do princípio da não coincidência plena entre os dois no seu modo de manifestar-se, a dialética materialista-histórica entende que o avançar do conhecimento do fenômeno até a sua essência é feito por meio da abstração e da análise lógica, pelas quais se "avança do conhecimento do fenômeno à essência, do conhecimento do imediato, externo ao mediato, interno" (ROSENTAL, STRIKES, 1960, p. 55, tradução das autoras). A expressão fenomênica da essência se dá, assim, por uma forma que designa a sua aparência, ou a essência em sua imediatez.

A dialética da essência e aparência e da forma e conteúdo, que não podem ser vistas de modo dicotômico e apartado, são fundamentais para pensar a operacionalização da mediação como categoria do sistema dialético.

Marx, ao partir da análise da mercadoria, demonstrou as contradições da sociedade burguesa e a essência do modo de produção capitalista, compreendendo esta forma específica e trivial como a aparência de um modo historicamente determinado de realização do trabalho nas sociedades de classes, cuja essência é a apropriação, pelo 
capital, do trabalho não pago. Ao refletir sobre as "múltiplas determinações" da forma-mercadoria, ele situa a categoria no plano da criação mútua entre produção e consumo: "a produção é imediatamente consumo e o consumo é imediatamente produção" (MARX, 2011, p. 64). É pela mediação da produção que a mercadoria passa a se diferenciar de sua determinação essencial, o seu valor de uso, o qual, pela mediação, se converte em uma nova forma, o valor de troca. A forma valor de troca é novamente mediada por diversas outras formas, como a forma-dinheiro e a forma-lucro, assumindo uma aparência do modo como se organizam as forças produtivas e as relações sociais de produção, historicamente determinadas pela dinâmica de acumulação do capital. Assim, nas sociedades capitalistas, diversas formas (como a forma-informação) mediam o modo como a produção material e a reprodução social se articulam tomando uma aparência de naturalidade. É neste sentido que as formas históricas podem ser pensadas como modos de existência, ou aparência, das relações capital-trabalho e também das lutas em que consistem essas relações (GUNN, 1987).

Neste processo, Marx evidencia o caráter fantasmagórico, ou fetichista, do mundo das mercadorias, oriundo do peculiar caráter social do trabalho nas sociedades capitalistas e que pode ser apreendido por trás da existência imediata da circulação, através de suas mediações. 0 caráter fetichista da mercadoria decorre do fato de esta se apresentar, em sua imediatez, como um objeto destinado à satisfação de necessidades e não como incorporação de um trabalho historicamente determinado, baseado na extração do mais-valor, resultado de outras mediações.

As expressões "forma" e "aparência", como adverte Gunn (1987), exigem uma problematização mais aprofundada. Ao pensar a operação da mediação no marxismo, o autor aponta que a forma ou aparência de algo pode ser compreendida como seu modo de existência. Dialeticamente, a forma não é entendida como oposta ao conteúdo e a aparência em oposição à realidade ou essência do "algo" em si. O sentido relevante para a mediação no âmbito da questão filosófica histórica em torno da essência-aparência não é dualista, mas dialeticamente constitutivo, como consigna o autor.

Assim:

essência não é algo além ou por trás da aparência, mas, só porque é a essência que existe, a existência é aparência. A relação entre aparência e essência aqui prevista é não dualista, na medida em que é dentro e por sua aparência que a essência é. A essência destaca-se diante de si como aparência, e é como, portanto, perante a si mesma que existe: a "aparência", em outras palavras, deve ser entendida não como um substantivo passivo (um véu ou 
capa inerte), mas como um "aparecendo", ou seja, em um sentido que alude à atividade do verbo (GUNN, 1987, p.3, tradução das autoras)

Gunn (1987) lembra ainda que no decurso histórico de expansão capitalista, as contradições inerentes à forma-mercadoria não são suprimidas, mas ganham uma nova forma a partir da qual elas adquirem espaço para se mover e se organizar. Neste sentido, a contradição é colocada sob uma nova forma, ou seja, é re-formada, a partir de outras mediações (GUNN, 1987; MARTINS, 2019a).

A perspectiva de análise da mediação como categoria vinculada à contradição foi fundamental para o trabalho de Martín-Serranou, responsável por inserir, no âmbito da Íbero-América, o termo no campo da Comunicação, desenvolvendo-o de um ponto de vista lógicosemiológico.

\section{A mediação social de Martín Serrano}

Manuel Martín Serrano, ao identificar que as movimentações revolucionárias de maio de 1968, embora fossem fruto das agudas contradições do capitalismo evidenciadas durante uma forte crise, não implicariam em uma transformação da totalidade do sistema, mas no seu reforço, levantou a hipótese de que tal fato decorreria da capacidade de o sistema operar com eficazes mecanismos de ajustes, os mecanismos de mediação. Tais mecanismos são destinados à adaptação dos sujeitos e se utilizam da própria contradição para a reprodução do sistema em estado de contradição. À essas operações de ajustes e de produção da ordem ele denominou "mediação social".

O livro La Mediación Social, que resulta de uma pesquisa de porte sócio-histórico realizada pelo autor entre os anos de 1969 e 1975, parte da consideração de que as sociedades capitalistas industrializadas evoluíam naquele momento de modo contraditório, trazendo outras formas de organização das relações sociais em todos os seus níveis (econômico, cultural e político). Mas, ao contrário do que se esperava, as contradições exibidas no momento da passagem das sociedades industriais para as "pós-industriais", ao invés de tornarem cada vez mais inviável o sistema, o reforçava (MARTÍN SERRANO, 2008, p. 16).

Isto podia ser visto, por exemplo, na incorporação, pelo capital, dos discursos que colocavam em xeque as formas de organização da produção pautadas na rigidez fordista, bem como das críticas dirigidas ao próprio capitalismo. A incorporação da noção de flexibilidade do trabalho, por exemplo, foi elemento importante para as novas formas de realização e controle do trabalho na saída da crise, que culminaram na ampliação da 
exploração. De modo semelhante demandas do feminismo pela ocupação do mercado de trabalho pelas mulheres foram subsumidas de modo que estas não incidissem em termos estruturais sobre a divisão internacional, racial e sexual do trabalho e possibilitassem a ampliação dos "exércitos de reserva".

A função dos mediadores é, de maneira geral, produzir no nível cognitivo modelos de ajuste que diminuem a dissonância existente no nível real entre a inovação tecnológica, a mudança cultural e a organização social. A mediação tem em vista ordenar a realidade, o que é feito neste momento histórico pela sua hiper-fragmentação, pelo ocultamento de suas contradições e pela correção dos desajustes sobre os sujeitos, obrigados a adaptar-se continuamente às transformações em curso (MARTINS, 2019b).

Como a contradição reproduz a ordem contraditória e como a alienação produz a identidade? (MARTÍN SERRANO, 2008). Esta questão pode ser resumida como o centro da teoria de Martín-Serrano exposta em sua obra mais emblemática.

A produção de um estado de crise constante que ultrapassa a esfera do econômico e atinge todos as instâncias da vida foi, segundo ele, uma das estratégias fundamentais de mediação na nova forma de organização do capitalismo representada pela globalização. Ela trouxe como consequência o imperativo da necessidade de adaptação frequente, exigindo cada vez mais a atuação de "mediadores" para que a ordem seja implantada. A atuação dos mediadores, que acontece por meios institucionais, materiais e simbólicos, é dirigida, assim, para que as contradições do sistema sejam gerenciadas como desequilíbrios individuais, implicando em correções sobre os sujeitos individualmente.

A imposição da necessidade permanente de adaptação dos indivíduos aos avanços tecnológicos contínuos, que supostamente trariam o bem-estar, o desenvolvimento humano e a ampliação das liberdades, é uma das expressões da mediação social que incide sobre o imaginário coletivo. Na configuração do capitalismo neoliberal, quando as tecnologias se convergem, significativamente, para a informação e a comunicação, o fetiche da técnica, cumpre um importante papel mediador.

A forma-informação, nesta perspectiva, opera na produção de modelos de ordem, o que faz com que suas mediações possam ser compreendidas como ajustes, sempre renovados e também tensionados.

Quando a mediação introduz um modelo de ordem na informação para oferecer uma visão estável do mundo com a finalidade de controle social, a informação deixa de ter por objeto a realidade 
original, "o que ocorre". Pelo contrário, é por meio do "o que ocorre" que se trata de explicar a ordem. O mediador toma seus próprios códigos como o assunto da comunicação, usando o conteúdo como um objeto ilustrativo. Ele impõe o primado da infraestrutura, da ordem, sobre o acontecer... [Logo], definimos a mediação como a atividade de controle social que impõe limites ao que poderia ser dito, e às maneiras de dizê-lo, por meio de um sistema de ordem. (MARTÍN SERRANO, 2011, p. 25)

A esses modelos que operam no nível cognitivo, o autor denomina "modelos de ordem", ou "modelos mediadores".

De um ponto de vista formal, a mediação equivale ao sistema de regras e de operações que se aplicam a qualquer conjunto de fatos ou de coisas pertencentes a planos diferentes da realidade, para introduzir uma ordem. A mediação que opera, por exemplo, a televisão, é realizada através da produção de ícones que tornam frágeis as barreiras entre o meio natural e o meio artificial e se processa, fundamentalmente, por meio de um código constituído por um repertório de regras de formação a partir das quais pode gerar-se um número de mensagens indefinidas, mas equivalentes de um ponto de vista normativo. Nesse sentido, uma visão de mundo se conserva enquanto esse repertório de regras de formação, ou seja, a estrutura do código, se mantém estável, ainda que o conteúdo explícito das mensagens se altere. A chave não estaria, segundo o autor, em quais elementos do acontecer se incluem nas mensagens, mas como esses elementos se relacionam entre si. (MARTÍN SERRANO, 2008). É precisamente aí que o manejo da ideologia se situa mais a nível do código do que na estrutura do que entendemos tradicionalmente como conteúdo. É esta operação que torna perfeitamente exequível que um conteúdo "contra-hegemônico", neste sentido, seja mobilizado como elemento reprodutor da hegemonia. Em outros termos, trata-se do princípio da "ordem pelo ruído", como o ciberneticista Heinz von Foerster nos legou.

A partir do momento em que a análise é transferida do conteúdo para os códigos, abre-se o caminho metodológico que permite a identificação dos códigos de controle social através do estudo da coerção lógica (MARTÍN SERRANO, 2008). O fundamento é, segundo Martín Serrano (2008), que um modelo ideológico sempre tenha um modelo lógico, o que o torna coerente e compreensível. Pode-se então partir

da análise de restrições lógicas para entender as restrições sociais, embora, na realidade, a ordem de dependência seja inversa. No processo de mediação, o controle social é realizado substituindo o 
sistema de constrições expresso pelos códigos sociais por um sistema de relações formais. Os julgamentos de valor são passados para os julgamentos de relações (MARTÍN SERRANO, 2008, p. 107, tradução das autoras).

O autor lembra ainda que para não por em risco a estabilidade dos sistemas normativos e garantir a reprodução da ordem estabelecida, os mecanismos de controle social centram-se em neutralizar os possíveis efeitos revolucionários da tecnologia televisiva, colocando-a à serviço dos fins institucionais da sociedade pós-industrial, especialmente o de produzir uma visão de mundo coerente com as necessidades de reprodução do capital. A função informativa da televisão como meio se torna, assim, contingente ante à sua função institucional (como mediador social).

A televisão resolve as contradições existentes no plano dos códigos, traduzindo os códigos gerais que permitem os meios icônicos a códigos particulares próprios da cultura abstrata. Os códigos particulares facilitam o controle das visões de mundo, segundo Martín Serrano (2008), porque reduzem as possíveis interpretações do acontecer que se mostra através das imagens. Para conservar o sistema normativo vigente, a televisão recupera o controle sobre o referente duplicando-o, ao relacionar as imagens com significados pertencentes a um nível separado do contexto real (MARTÍN SERRANO, 2008). De maneira geral, trata-se de adicionar um referente implícito ao discurso televisivo relacionado aos sistemas normativos que o mediador deseja conservar. Desta forma, a informação do mediador deixa de ter por objeto "a realidade original ou o que acontece", mas, ao contrário, o mediador, por meio do que ocorre, tem em vista explicar e reafirmar a ordem, fazendo uso do acontecer para reproduzir o código. As normas, ajustadas aos processos de produção e reprodução social, passam a ser o verdadeiro referente da comunicação e o código assume uma função determinante na produção de uma ordem. Embora tenha tido pouca reverberação no campo de estudos da informação, a perspectiva de Martín Serrano coloca questões relevantes para pensarmos os objetos info-comunicacionais sob a ótica das mediações, especialmente abrindo vias para compreendê-los como mecanismos de ajustes operados, não sem resistências, por meios cognitivos, materiais e institucionais.

A partir das contribuições de sua teoria e dos referenciais dialéticos anteriormente apontados, vislumbra-se ser possível um exercício de aplicação da categoria mediação em sua acepção dialética na construção e compreensão de objetos singulares com os quais se ocupa o campo da Ciência da Informação. Para isso, escolhemos uma expressão 
informacional bastante comum do tempo presente: as chamadas "microformas documentárias" que circulam na Internet.

\section{Micro-formas documentárias: uma aproximação pelas mediações}

O espaço da produção e consumo de informação nos dispositivos da Internet, sobretudo nas chamadas "redes sociais", tem sido marcado, há alguns anos, pela presença de formatos específicos de documentos que guardam duas características principais: são realizados pelos mais diversos indivíduos, grupos e instituições e, por meio de práticas coletivas, se disseminam de maneira exponencial, gerando outros novos documentos.

"Micro-formas documentárias" é o nome dado por Jeanneret (2015), no âmbito dos estudos da "economia política dos textos e das escritas na web", para designar alguns destes formatos de documentos. Dentre eles podemos destacar os memes, que têm como aspectos marcantes a composição híbrida de linguagens, o uso do humor, da ironia, da intertextualidade e da retórica e sua grande capacidade de se disseminar. Estas pequenas formas são caracterizadas pela rapidez da transmissão, pela intensidade da reprodução que possibilita a ampla propagação de mensagens curtas e pela sua realização em um universo onde predominam a requisição ("necessidade" ou "obrigação" de estar no espaço), a enunciação mínima, o compartilhamento de objetos já construídos por outros, o uso de documentos produzidos no espaço privado e a captura de discursos midiáticos em favor de um fluxo de comunicação de segundo nível (JEANNERET, 2015).

Ao pensar as formas documentárias que circulam nas "redes sociais", compreendidas, por sua vez, como "dispositivos de instrumentação das trocas documentárias de uma natureza particular" (JEANNERET, 2015, p. 17), o autor, a partir dos trabalhos de Candel, Jeanne- Perrier e Souchier (2012) aponta que se trata de uma:

conformação densa e altamente automatizada de "pequenas formas", formatos de escrita pré-formatados, compactos e padronizados, combinados a uma lógica de fragmentação e de miniaturização extremas. Essas ferramentas de escrita automatzadas permitem o controle do não- especialista sobre gestos documentários simplificados e mínimos de coleta, de conservação, de transmissão e de classificação de unidades textuais e documentais tornadas acessíveis, não por uma mediação institucional de saber, mas pelo exercício de predileções individua is 
e coletivas diversas. Uma espécie de escritório de curiosidades aparelhado (JEANNERET, 2015, p. 18)

Jeanneret (2015) lembra que o surgimento desse tipo de dispositivo está implicado com uma intervenção na trajetória das comunicações sociais que evidencia uma "pretensão real de condicioná-las, instrumentalizá-las e regê-las" (JEANNERET, 2015, p. 17). Para compreender as micro-formas é preciso, portanto, vislumbrá-las por uma perspectiva de longa duração, a partir da "dialética entre formatos documentários e figuração da relação social", de modo a verificar sua inscrição em uma série histórica, ou seja, no mesmo continum onde se situam a Indústria Cultural e toda a institucionalidade dos textos e das mídias.

A chegada desses dispositivos, lembra Jeanneret (2015), consolida uma tendência na representação do potencial infocomunicacional das mídias informatizadas, de modo que ela se localiza em uma série. A partir de um breve recuo histórico é possível constatar, segundo ele, que diversas tendências foram objeto de valorizações e de instrumentalizações variadas e sucessivas que podem ser vistas nas diferentes fases que marcam as formas de escritas na web: uma primeira caracterizada pelo predomínio do hipertexto, uma seguinte da imersão ilusionista no "virtual" e mais tarde das escrituras criativas da "multimídia". Se no início de 2000 houve certa rejeição do visual e forte retorno do texto contínuo, valorizando a escrita colaborativa, já na metade da primeira década, com - Facebook e o Twitter, passaram a prevalecer o "regime do contato e o imediatismo do gesto: de curtir, de compartilhar, de indexar pelas "tags" (JEANNERET, 2015). O autor lembra, a partir de Labelle (2007), que essas plataformas documentárias mínimas aparecem como decorrência do princípio da panóplia, exprimindo uma coleção de roteiros de interação altamente heterogêneos, mas todos padronizados.

Assim:

a grande comodidade de uma panóplia constituída de formas mínimas "sob a mão" autoriza uma polivalência sem precedentes das produções documentárias. Afastamo-nos do modelo "estratégico" das profissões da comunicação, em que nos aplicamos a fazer coincidir tanto quanto possível uma finalidade, um gênero, um tipo de discurso. Aqui, ao contrário, o que alimenta o fluxo constante da atenção e da inscrição é a plasticidade das formas que 
podem variar desde o espaço do saber ao do testemunho particular e da troca comercial (JEANNERET, 2015, p. 23)

A enunciação em gestos mínimos (coletar, transmitir, destacar, etiquetar) favorece significativamente o crescimento dos fluxos de troca, que também são regidos pela lógica do "conatus discursivo" (CANDEL, 2007 apud JEANNERET, 2015), que conduz cada um a escrever e publicar algo sobre si. O que diferencia essas formas dos blogs e a experiência dos fóruns e plataformas de escrita colaborativa, que não se tornaram tão predominantes e duráveis porque demandavam grande investimento em escrita, segundo ele, é o fato de prover "panóplias de formas microdocumentárias" e, em função disso, solicitar "enunciações mínimas (expressão lacônica, transmissão do já escrito, empréstimos furtivos), permitindo a estruturação de um espaço de "presença social abundante e diversa" (JEANNERET, 2015).

Assim, as micro-formas documentárias que se exibem nas "redes sociais" remetem à figura do labirinto, que se caracteriza pelo fato de a experiência estar sempre restrita a um espaço particular, nunca fornecendo uma visão do todo. Isto ocorre justamente porque a indústria que organiza e gere estes formatos "funda-se jogando com a dimensão criativa dos usos, de modo a recuperar a dinâmica para instrumentalizála, especialmente assegurando a ocupação dos espaços da leitura, da escrita e da atenção. Em resumo, "uma arte de dispor as formas para dispor os conteúdos" (JEANNERET, 2015, p. 25). A compreensão dessa dinâmica exige, neste sentido, distinguir "os planos de mediação que foram integrados e que acabam se apresentando como indiscerníveis".

Para que estes planos sejam discerníveis, podemos inserir este objeto na perspectiva histórica da totalidade, buscando as mediações desta manifestação singular, em um contexto particular: o das "sociedades da informação". Contemplar a particularidade histórica em que se realizam as micro-formas documentárias é importante para o exercício de aproximação a estas práticas e artefatos para além dos seus possíveis significados imediatos.

A particularidade histórica das "sociedades da informação", ou seja, de uma nova forma assumida pelo capitalismo global como resposta à crise dos anos de 1970, é marcada especialmente pela informatização geral das mais diversas atividades, que possibilitou tanto a reorganização da base produtiva, quanto a expansão do econômico e da lógica da formamercadoria para todas as esferas da vida. Esta saída, proporcionada por uma "mediação informacional", ou seja, por ajustes decorrentes da forma- 
informação orientados às relações capital/trabalho e economia/cultura, culminou na instituição de uma nova lógica de acúmulo, cujas principais características têm sido a predominância da valorização do capital financeiro, o intenso movimento especulativo do capital, a intelectualização dos processos de trabalho e de consumo (BOLAÑO, 2000 ; 2018) e a incidência sobre a produção de subjetividades. É neste sentido que podemos pensar as micro-formas documentárias como uma forma específica da mediação social, especialmente vinculada à produção de uma "racionalidade neoliberal" (LAVAL; DARDOT, 2016).

A forma neoliberal do capitalismo vem se consolidando, segundo Laval e Dardot (2016), graças a uma normatização subjetiva de um tipo muito particular e por meio do estabelecimento de "novas regras de controle em que cada sujeito foi levado a conceber-se e comportar-se em todas as dimensões da vida, como um capital que deve valorizar-se" (LAVAL; DARDOT, 2016, p. 203). É neste sentido, conforme aponta Lopes (2006), que a forma-informação se tornou crucial para o capitalismo rentista e neoliberal: não apenas por constituir-se na matéria adequada para o trabalho produtivo e produção de valor para o capital, mas especialmente, pela sua função de organização de um regime de produção de subjetividade. A subjetividade é, mais do que nunca, um dos elementos fundamentais da produção do valor e de suas correspondentes formas de controle, bem como do ajuste entre a produção e a reprodução social.

Nesse quadro, se a televisão foi fundamental para produzir, não sem resistências, modos de vida ou subjetividades adequados aos valores necessários para a reprodução do capital monopolista e para a circulação das mercadorias (MARTÍN SERRANO, 2008; BOLAÑO, 2000), a produção das micro-formas documentárias que disseminam e consolidam cenários das práticas também pode ser compreendida no âmbito da grande "estrutura mediacional" em que se converteu a Internet, ao subsumir a velha indústria cultural do século XX (BOLAÑO, 2018). Além de proporcionar enormes volumes de dados a partir dos quais, por meio do trabalho intelectual, gera-se valor, sua importante mediação é viabilizar, a partir da grande "diversidade de conteúdos" e das práticas compartilhadas, uma racionalidade adequada ao momento neoliberal (MARTINS, 2019a, p. 17).

Em um momento histórico em que o sujeito se converte na "empresa de si" (LAVAL; DARDOT, 2016), desempenham um papel crucial as plataformas microdocumentárias na emergência de um espaço de visibilidade, onde a posição do amador reconhecido se torna um meio de conquistar o estatuto de especialista (JEANNERET, 2015) e onde é 
possível angariar, por um simples gesto ou vínculo, um capital social que pode ser amplamente exibido, valorizado e convertido.

Sem desconsiderar que a produção da hegemonia é sempre processual, aberta e tensionada, a mediação dialética problematiza, no entendimento das micro-formas documentárias, como a organização hegemônica pode operar na Internet, em alguma medida, à despeito da ampla diversidade de mensagens, no reforço a códigos que estabelecem uma lógica comum para todas as práticas: a lógica da racionalidade neoliberal, lógica que pulveriza os sentidos para que se percam da totalidade histórica e que instrumentaliza os afetos e a sociabilidade como meios de acúmulo do capital.

Um olhar dialético para as "micro-formas documentárias" pode revelar, pelas mediações, ser a heterogeneidade da informação e de sentidos produzidos e circulantes a partir dos dispositivos da infotelecomunicação uma aparência necessária de um modo específico de produção econômica e reprodução social cuja essência é a ampliação ilimitada, para todas as esferas da existência humana da exploração dos sujeitos pelo capital, bem como de sua colonização subjetiva.

Este modo de pensar a categoria mediação a partir da articulação dialética entre os sentidos e significados que atravessam os fenômenos informacionais e os modos de produção econômica e reprodução social, tendo em vista a particularidade histórica de sua expressão, pode partir dos mais diversos objetos concretos que se apresentam sob a forma de práticas, comportamentos e produtos de informação e que se convertem em objetos de pesquisa (DAVALLON, 2006).

Neste sentido, assim como Marx partiu da forma-mercadoria é possível partir de uma expressão informacional singular, como uma microforma documentária (mediada pelas linguagens e sistemas simbólicos, mediada pelos "modos de fazer" das plataformas de comunicação, mediada pela indústria da cultura, mediada pelas formas de subsunção do trabalho ao capital, mediada pelos dispositivos de produção de subjetividades etc.), buscando compreender a informação a partir dos seus nexos constitutivos, ou dos processos totalizantes da realidade social, nos quais se inscrevem todos os objetos científicos e os múltiplos olhares sobre eles.

\section{Conclusões}

Como categoria dialética, a mediação está fundamentalmente relacionada à existência do ser social, ao movimento contraditório do real e do pensamento, às suas determinações e ao processo de conhecimento a partir das articulações estabelecidas entre as partes de uma totalidade complexa. Está, portanto, vinculada às ideias de historicidade, 
contradição, totalidade, essência, aparência, dentre outras que fundam o sistema dialético e que supõem um processo lógico e histórico de articulação (MARTINS, 2019a).

$\mathrm{Na}$ "epistemologia social" da Ciência da Informação, a perspectiva dialética da mediação sublinha a conexão necessária entre os sentidos mobilizados a partir dos processos e artefatos informacionais e a produção material e concreta da realidade.

Nessa direção, o olhar dialético para as mediações é convergente aos preceitos da totalidade, da tensionalidade e da historicidade apontados por Cardoso (1994) na fundamentação de um "campo da informação social", compreendendo uma perspectiva indissociavelmente teórica e metodológica que contribui para a construção de conhecimento sobre os objetos de interesse da Ciência da Informação, tendo em vista a complexidade dos processos sócio-históricos que lhes são inerentes.

Através da consideração do desenvolvimento lógico-filosófico do termo e das possibilidades que ele abre, a categoria mediação/mediações pode se operacionalizar, assim, epistemológica e metodologicamente, vislumbrando os nexos constitutivos pelos quais se realizam os "fenômenos" ou "objetos info-comunicacionais" que se quer conhecer, de modo que a informação, em suas diferentes expressões, possa ser percebida em sua essência, considerando o necessário movimento histórico do real e do pensamento sobre ele.

\section{Referências}

ABBAGNANO, Nicolas. Dicionário de filosofia. São Paulo: Martins Fontes, 2007.

ALMEIDA, Marco Antônio de. Mediação cultural e da informação: considerações socioculturais e políticas em torno de um conceito. In: ENANCIB, 8, 2007, Salvador, BA. Anais [...] Promovendo a inserção internacional da pesquisa brasileira em Ciência da Informação. Salvador, BA: Universidade Federal da Bahia, 2007. p.1-16

BOLAÑo, César. Indústria cultural, informação e capitalismo. São Paulo: Hucitec/Polis, 2000.

BOLAÑO, César. Crítica e emancipação nos estudos da informação, da comunicação e da cultura. Epitic, Rio de Janeiro, v.20, n.1, p. 100-110, 2018.

BOTTOMORE, Tom. Dicionário do pensamento marxista. São Paulo: Zahar, 2010. 
CARDOSO, Ana Maria Pereira. Retomando possibilidades conceituais: uma contribuição à sistematização do campo da informação social. Revista da Escola de Biblioteconomia da UFMG, Belo Horizonte, v. 23, n. 2, p. 107$114,1994$.

CIAVATTA, Maria. O conhecimento histórico e o problema teóricometodológico das mediações. In: FRIGOTTO, G.; CIAVATTA, M (Org.). Teoria e educação no labirinto do capital. Petrópolis: Vozes, 2001. p. 2017- 245.

DAVALLON, Jean. L'économie des écritures sur le web. Paris: Hermès Science- Lavoisier, 2012. v. 1.

DAVALLON, Jean. A mediação: a comunicação em processo? Prisma.com, n 4, p. 3-36, 2007. Disponível em:

http://prisma.cetac.up.pt/A mediacao a comunicacao em processo.pdf. Acesso em: 14 de mai. 2019.

DAVALLON, Jean. Objeto concreto, objeto científico, objeto de investigação. Prisma.com, n.2, p. 33-48, 2006.

GUNN, Richard. Marxism and mediation. Common Sense, n. 2, jul, 1987. HEGEL, Georg Wilhelm Friedrich. Ciência da Lógica: a doutrina do Ser. Petrópolis: Vozes, 2017.

INWOOD, Michael. Dicionário Hegel. Rio de Janeiro: J. Zahar, 1997. JAPIASSÚ, Hilton, MARCONDES, Danilo. Dicionário Básico de Filosofia. Rio de Janeiro: Zahar, 2001.

JEANNERET, Yves. A relação entre uso e mediação no campo de pesquisa em informação e comunicação na França. RECIIS, Revista Eletrônica de Comunicação, Informação e Inovação em Saúde, v. 3, n. 3, p. 25-34, 2009.

JEANNERET, Yves. Analisar as redes sociais como dispositivos infocomunicacionais: uma problemática. In : TOMAEL M.I. ; MARTELETO, R.M. (Org.) Informação e Redes Sociais: interface de teorias, métodos e objetos. Londrina: Eduel, 2015, p. 11-31.

KOFLER, Leo. História e dialética: estudos sobre a metodologia da dialética marxista. Rio de Janeiro: Editora UFRJ, 2010.

LALANDE, André. Vocabulário técnico e crítico da filosofia. São Paulo: Martins Fontes, 1993. 
LAVAL, Christian; DARDOT, Pierre. A nova razão de mundo. São Paulo: Boitempo, 2016.

LOPES, Ruy Sardinha. Informação, conhecimento e valor. 2006. $174 \mathrm{f}$. Tese (Doutorado em Filosofia) - Faculdade de Ciências Humanas e Filosofia, Universidade de São Paulo, 2006, 207p.

MARTELETO, Regina Maria. Redes sociais, mediação e apropriação de informações: situando campos, objetos e conceitos na pesquisa em ciência da informação. Tendências da Pesquisa Brasileira em Ciência da Informação, Brasília, v .3, n. 1, p.27-46, jan./dez., 2010. Disponível em: https://www.arca.fiocruz.br/handle/icict/2247. Acesso em: 13 mai. 2019.

MARTELETO, Regina Maria. Epistemologia social e cultura digital: reflexões em torno das formas de escritas na web. Em Questão, Porto Alegre, v. 21, n. 3, p. 9-25, 2015.

MARTELETO, Regina Maria. Redes sociais, mediação e apropriação de informações: situando campos, objetos e conceitos na pesquisa em Ciência da Informação. Tendências da Pesquisa Brasileira em Ciência da Informação, Brasília, v.3, n.1, p.27-46, jan./dez. 2010. Disponível em: https://www.arca.fiocruz.br/handle/icict/2247. Acesso em: 30 ago. 2019.

MARTÍN-BARBERO, Jesus. De los medios as la mediaciones: comunicación, cultura y hegemonía. Barcelona: Ed. Gustavo Gili, 1987.

MARTÍN SERRANO, Manuel. La mediación social: Edición conmemorativa del 30 aniversario. Madrid: Akal, 2008.

MARTÍN SERRANO, Manuel. Mediación y sociedad: voz mediación. Chasqui-Rev.Latinoamericana de Comunicación, n. 114-115, p. 24-26, 2011.

Disponível em:

https://revistachasqui.org/index.php/chasqui/article/view/550/550. Acesso em:10 de maio 2019.

MARTINS, Ana Amélia Lage. Mediação: reflexões no campo da Ciência da Informação. 2010. 252 f. Dissertação (Mestrado em Ciência da Informação), Escola de Ciência da Informação, Universidade Federal de Minas Gerais, Belo Horizonte.

MARTINS, Ana Amélia Lage. Mediação: categoria ontológica, lógica, epistemológica e metodológica. Investigaciones Bibliotecológicas, v. 33, n. 80, p. 133-154, 2019a. Disponível em: http://revib.unam.mx/ib/index.php/ib/article/view/58036/52003. Acesso em: 20 de ago. de 2019 
MARTINS, Ana Amélia Lage. Em torno da mediação: contribuições para fundamentação teórico-epistemológica da categoria nos estudos da informação. Ciência da Informação em Revista, v. 6, n. 1, $2019 \mathrm{~b}$.

MARTINS, Ana Amélia Lage. Mediação: perspectivas dialéticas. In: COLLOQUE SCIENTIFIQUE INTERNATIONAL DU RÉSEAU MUSSI, 4. Actes [...] Lille: Université Lille3, p. 63-74, 2018.

MARX, Karl. Grundrisse. São Paulo: Boitempo, 2011.

MARX, Karl. Contribuição à crítica da economia política. São Paulo: Expressão Popular, 2008.

MÉSZÁROS, Istvan. Para Além do Capitat rumo a uma teoria da transição. São Paulo/SP: Boitempo, 2002.

MORA, José Ferrater. Dicionário de Filosofia 5. ed. Lisboa: Dom Quixote, 1982.

O'CONNOR, Brian. The concept of mediation in Hegel and Adorno. Bulletin of Hegel Society of Great Britain, n. 39/40, p. 84-96, 1999.

PORTUGAL, Sílvia. Contributos para uma discussão do conceito de rede na teoria sociológica. Coimbra: CES/Universidade de Coimbra, Oficina no. 271, 2007.

PUGLIESI, Márcio; BINI, Edson. Pequeno diccionario de filosofia. São Paulo: Hemus, 1997.

RAMBALDI, Enrico. Mediação. In: Enciclopédia Einaudi, v. 10, Dialectica. Lisboa: Imprensa Nacional - Casa da Moeda, 1989, p. 143-174.

ROSENTAL, Mark Moisevich; STRAKS, G.M. Categorias del materialismo dialectico. Ciudad de Mexico: Grijalbo, 1960.

1 Para uma abordagem sobre a dimensão ontológica, lógica, epistemológica e metodológica da mediação na dialética consultar: MARTINS, A. A. L. Mediação: categoria ontológica, lógica, epistemológica e metodológica. Investigacion Bibliotecologica, v. 33, n. 80, p. 133-154, 2019.

$\underline{2}$ O processo histórico de constituição do gênero humano, a passagem do ser puramente biológico para o ser social contou com a forma de mediação fulcral do trabalho, uma vez que foi por meio da relação entre humanos e natureza mediada pelo trabalho que a satisfação das necessidades humanas, orientada não mais pela lógica instintiva do animal, mas por uma ação conscientemente 
direcionada a um fim, se tornou possível. O trabalho (e os instrumentos de trabalho) são, assim, para Marx, mediações fundamentais para que o ser social exista, ou em outros termos, a condicionante da existência humana, em todas as épocas, a partir da qual se constitui o ser social.

$\underline{3} \mathrm{O}$ autor observa que Marx questiona, frequentemente, o porquê de as relações de produção assumirem determinadas formas. As "formas" em questão são a forma-mercadoria, a forma- valor, a forma-dinheiro, a forma-salário etc., entendidas como mediações da relação capital-trabalho e das relações de classes sob o capitalismo (GUNN, 1987).

4 Manuel Martín Serrano é professor e pesquisador da Facultad de Ciencias de la Información, da Universidad Complutense de Madrid.

$\underline{5}$ Uma discussão sobre as micro-formas documentárias e mediações foi feita na $4^{a}$ Jornada Internacional da Rede Mussi, realizada na Escola de Ciência da Informação da UFMG, em 2019. 